\title{
Analysis on the Product Design According to the Low Carbon Conception
}

\author{
Pan Deng \\ Xi’an International University, Xi'an Shaanxi, 710077
}

Keywords: Low Carbon Design; Conception; Product Design; Analysis

\begin{abstract}
Chinese government, the conception of sustainable development has been accepted by the public gradually; the low carbon conception also has been brought out and applied on the design of the products. The product design of the low carbon conception aims for taking the best of the environment-friendly material, increasing the products' value of recycling, decreasing the carbon gas that is produced during the utilization of the product, protecting the environment and keeping the sustainable development of the environment, so as to promote the sustainable development of the economy and society of China. This thesis analyzes the low carbon design and the low carbon product, and then discusses the modern product design according to the low carbon conception.
\end{abstract}

In the traditional developmental model of economy, the environment has been over explored by the people, and the ecology also has been influenced by the activities of the people; especially, the air surround us has been polluted badly. Therefore, many environmental researchers have noticed that this kind of destructive way of production will leads to many serious problems. By the propaganda and supervision of the Chinese government, the conception of sustainable development has been accepted and put into practice by the public gradually. The low carbon design conception fully emphasizes saving natural resources and energies, and taking the best of the environmental protection methods, so as to promote the harmonious relationship between the human being and the nature, to promote the balance of the ecology and the environment, and to promote the sustainable development of the society and the economy. To achieve this, all the designers must try their best to design good products, all the enterprises must insist on manufacturing the products that are environment-friendly. And the some time, the supervision and propaganda from all walks of life is the most important thing.

\section{Analyses on low carbon design and low carbon product}

Low carbon design means to integrate the low carbon conception with the product design so as to reduce the pollution and destruction of the environment. We could understand the conception that it is a necessary way to reduce the greenhouse gas during the whole lifetime of the product----from the initial design to manufacture, storage, transportation, utilization, and the recycling at last, so as to reduce the bad influence that is caused by the economic development [1]. The low carbon design not only pays attention to the creative aspects of the products, but pays more attention to the low exhaust, low consumption of resources, and low pollution during the whole lifetime of the products. It not only means a new form of expression, but a new way of life. For achieve the objective of low carbon conception, it is necessary to coordinate the relationship between the products and the human being well during the whole lifetime of the products. Therefore, the low carbon conception can not only be a kind of slogan, but a kind of attitude of life and a new way of production; it is a kind of new trend that could be achieved by means of design; it could improve the sense of social responsibility of every people.

The low carbon product means the product that could generate the greenhouse gas as least as possible during its whole lifetime. At present, there are many kinds of low carbon products, such as LED lights, synthetic paper, gas furnace, clean carbon, and so on. The features of the low carbon products are listed as blow. (1) It is environment-friendly. This feature means that the products should be environment- friendly in every phase of its lifetime. A low carbon product should satisfy 
the official definition of environment protection. (2) It is recyclable. This feature means when the life of a product will be over, it could be reused by designing and exploring once more, and prolong its using value; when the product can not be used any more, it could be disposed scientifically and reasonably, so as to reduce the damage to the environment. (3) It has the function of optimization. This feature means a product could not only ensure its intrinsic functions and its environment-friendly feature, but also develop some new functions which could meet the unlimited demands of the social and economic development, so as to actualize its most optimistic value.

\section{Design of the modern product}

The product design is a process that consumes a lot of resources and energies, it is close related to the daily life of people; so, to construct the low carbon and environment-friendly industries is very important, this also challenges the designer's abilities a lot. Because the consumers are the foundation for the designers, so the modern design should be fit for the needs of the social and economic development, both the designs and the manufacturing techniques should be accord with the requirements of environment protection.

The product design must show the conception design. Conception design is a series design activities, which have a certain procedure, organization, and objective, aims for fulfill the needs of the public after analyzing the custom's needs. Conception design could constantly improves the using values of the products by the ideology that to design a product from coarse to fine, from indistinct to distinct, and then from concrete to abstract [3].

The product design also should fulfill the requirement of the manufacture. This requires the structure design of the products should be scientific and reasonable according to the production techniques, so as to reduce the manufacturing cost when the enterprises manufacture the products on a large scale, and to ensure the quality of the product. At the some time, the structure of the products should saving the labor resources, reduce the raw material consumption, shorten production cycle, reduce manufacturing cost, and improve the product value.

\section{Product design according to the low carbon conception}

Material is the key factor that the designers should deliberate a lot. According to the low carbon conception, the designers should pay attention to the environment-friendly value when they choose the proper materials; they must choose the environment-friendly material so as to actualize the actual efficiency of the low carbon design conception. The designers should not only integrate the requirements of the manufacturing techniques, but also consider the actual selectable materials, and then, choose the proper materials that are recyclable and environment-friendly according to the principle of sustainable development. To choose the materials that have more environment-friendly features and that are easier to recycle could reduce the manufacturing cost effectively. For example, in order to improve the using efficiency of the woods, people use the bits of wood to manufacture desk, chair, or paper, and this avoid the forest being cut down. To take the best of the recyclable and environment-friendly materials can improve the utilization rate of the products, even the utilization rate after the product is designed again by the designers, so as to reduce the carbon gas and protect the environment. To use the environment-friendly material can facilitate people to recycle the products and improve the quality of the products. For example, according to the low carbon conception, people recycle the newspaper, old clothes, and waste plastic for saving some materials and reduce the carbon gas, so as to follow the request of the low carbon conception.

In the present products of driving force, battery is the main power supply, while the over utilization of battery and the unreasonable disposal bring a lot of environmental problems. So, during the process of product design, it is necessary to propagate the low carbon conception to the designers, to optimize the structure of the power supply, to show the ways of disposing the battery to the users, and to optimize the recycling and utilization of the battery. The traditional battery has some defectives such as the power supply is simplex; it is not recyclable, and so on; so the battery could not be utilized very well. Therefore, in the modern product design, the designers should fully 
take the best of all kinds of energies such as the solar power, the wind power, luminous power, etc, so as to optimize the structure of energy to the largest extent. At the some time, according to the low carbon conception, the designers should know very well about the tricks of the design, they also should know something about the new energies, so as to design the products that are of low carbon. For example, the modern electric torch and the toys of the children are rechargeable; even some products could generate electricity automatically. To optimize the structure of the power supply is not only an excellent conception that is accord with the low carbon conception, but protects the environment well, it has brought lots of conveniences to our daily life.

As the constant development of the science and the all kinds of technology, the manufacturing model should to be improved, as the some time, the updating speed of the products becomes faster and faster, and the lifetime of the products also becomes shorter and shorter, so that the resources are wasted badly, and environmental problem is serious. Therefore, during the process of product design, the designers should pay attention to prolonging the lifetime of the products, so as to protect the environment. Take the mobile phone for example, because its updating speed is very fast and it is very common in our daily life, so the update of the mobile phone wastes a lot of resources. So, many mobile phone manufactures have been finding the new materials so as to prolong the lifetime of the phone and the second-lifetime when the designers design it once more, so as to increase the functions of the products after the second design, so as to attract the consumers by the new ideas and the creativities of the products, and so as to slow down the updating speed of the products ${ }^{[4]}$.

\section{The influence by the low carbon conception on the product design style}

In the modern life of the public, people could find out all kinds of products anywhere; these products make our life colorful, and they service us all the time. But, some products have damaged the environment badly, so that the world has been polluted seriously, it brings a lot of environmental problems such as water pollution, air pollution, forest reducing, and so on. Therefore, the present product design emphasizes keeping the harmonious relationship between the human being and the nature and promoting the sustainable development, so as to promote the more harmonious relationship between the people and the environment. We should propagate the low carbon conception actively so as to let the public accept the new conception. Nowadays, as the rapid development of the technology and the society, the producers want their products are different from the others, this phenomenon ask the designers to design the products with different features, the functions of a product can endow the products with more value, and the products with the conception of low carbon could leads the people to live a low carbon life, and protect the environment effectively.

The design trend of low carbon has been raised by the designers; this kind of design style has become the pursuit of the public, even the humanized design style has been forgotten gradually. The humanized design style emphasizes designing the products from the needs of the users, and satisfying the needs of the users. Form this point of view, it is accord with the low carbon design conception, they all show the design conception that they take the users as the center. But the low carbon design conception stresses on the harmonious relationship between the people and the environment much more. It is necessary to take the people as the center and foundation in the product design activities; at the some time, it is also necessary to pay attention to the harmonious relationship between the people and the surroundings. The low carbon design conception is a new conception that the designers must follow, and many design conceptions that are related to the low carbon conception have been brought out, these new conceptions have been accepted by the public, and they have become the popular style that the designers have been highly prized ${ }^{[5]}$.

\section{Conclusion}

The low carbon design conception should emphasize saving natural resources and energy, improving the products' feature of environmental protection. Only by this could people get along well with the nature, and only by this could keep a balanced ecosystem and a sustainable developed 
economic system. It needs all the designers to strive for designing the low carbon products; it also needs all the enterprises to insist on the low carbon conception; further more, it needs all the people and the government to advocate the conception and supervise the implementation of the conception. The low carbon design is a developmental trend at present and in future, it is a kind of design conception that could to be shared, it is a key measure to create the low carbon new life, and it is the key point of the social reformation. The new product design will bring the new ways of production, and promote people to utilize the environmental materials and recycled materials so as to promote the enterprises to manufactory more low carbon products. Therefore, the enterprises would emphasize the harmonious relationship between the human being and the nature, this also would promote the sustainable development of the ecology and the environment, and promote the more harmonious relationship between the human being and the nature. Under this background, the conception of the low carbon design comes out, and it has been accepted by the public gradually. This conception will promote the sustainable development of the society and the economy, and promote the ecology and the environment become better and better.

\section{References}

[1] Li Fei, Liu Le. Research on the Product Design Base on the Low Carbon Conception[J]. Technology Trend, 2017, (17):141.

[2] Zhang Yiqi. Discussion on the Low Carbon Design Conception that is Used in the Package of Products[J]. Art Science and Technology, 2017, (04):244.

[3] Luo Yun. Discussion on the Form of Product and the Conception of Product Designation[J]. Industrial Design, 2016, (07):90+93.

[4] Zhong Lei, Zhu Yaoying. Try to Discuss the Low Carbon Conception that is Used in the Product Design[J]. Art and Design, 2015, (09):92-94.

[5] Zhang Sisi. Research on the Product Design Base on the Low Carbon Conception[J] Technology Trend, 2015, (13):179. 